\title{
JOSÉ BRAULIO AMAT Y JOSÉ MARÍA MARTÍN. DOS APORTACIONES AL GRABADO DEVOCIONAL DE LOS TEMPLOS DE SAN NICOLÁS DE BARI Y SANTA MARÍA LA BLANCA DE SEVILLA
}

\author{
JOSÉ BRAULIO AMAT AND JOSÉ MARÍA MARTÍN.TWO \\ CONTRIBUTIONS TO THE DEVOTIONAL ENGRAVING \\ OF THE TEMPLES SAN NICOLÁS DE BARI AND SANTA \\ MARÍA LA BLANCA OF SEVILLE
}

\author{
Jesús Rojas-Marcos GonzÁlez \\ Universidad de Sevilla, España \\ rojasmarcos@us.es
}

\begin{abstract}
En este trabajo damos a conocer dos obras inéditas en la producción de los grabadores sevillanos José Braulio Amat y José María Martín. Se trata, en concreto, de dos grabados devocionales vinculados con los templos de San Nicolás de Bari y Santa María la Blanca de Sevilla. Pertenecen, respectivamente, a los siglos XVIII y XIX. El primero de ellos, de Amat, es una representación de la escultura lignaria del referido santo titular; el segundo, de Martín, reproduce el martirio de San Juan Nepomuceno tal como se venera en su capilla de la citada iglesia de Santa María la Blanca.

Palabras clave: José Braulio Amat; José María Martín; Iglesia de San Nicolás de Bari; Iglesia de Santa María la Blanca; Grabado; Siglos XVIII-XIX; Sevilla.

In this paper we present two new works in the production of the sevillian engravers José Braulio Amat and José María Martín. It is, in particular, two devotional engravings related to the temples of San Nicolás de Bari and Santa María la Blanca of Seville. Belong respectively to the eighteenth and nineteenth centuries. The first one, of Amat, is a representation of the sculpture of the referred titular saint; the second one, of Martín, reproduces the martyrdom of Saint John Nepomuk as it is venerated in its chapel of the church of Santa María la Blanca.

Keywords: José Braulio Amat; José María Martín; Church of San Nicolás de Bari; Church of Santa María la Blanca; Engraving; Eighteenth and Nineteenth Centuries; Seville.
\end{abstract}


Sabida es la dedicación del Dr. D. Teodoro Falcón Márquez, catedrático emérito de la Universidad de Sevilla, al estudio de las iglesias de San Nicolás de Bari y de Santa María la Blanca de la ciudad de la Giralda. La primera de ellas, a la que también le unen vínculos personales, ha sido objeto de sus investigaciones desde sus inicios profesionales; la segunda, es un tema frecuente en su bibliografía durante los últimos veinticinco años. Por ello, estimamos que el homenaje que el Departamento de Historia del Arte de la Universidad hispalense rinde al citado profesor es un momento propicio para dar a conocer dos nuevas aportaciones sobre tan importante parcela de la religiosidad popular. En concreto, catalogamos, analizamos y reproducimos dos grabados inéditos vinculados directamente con los referidos templos sevillanos, que hoy constituyen una sola parroquia.

Uno y otro están inmersos en el ambiente artístico hispalense de la segunda mitad del siglo XVIII y principios de la siguiente centuria, donde la Real Escuela de las Tres Nobles Artes ejercía su benéfica influencia. Por entonces, los grabados eran objeto de una gran demanda popular, por su económica adquisición, por satisfacer las devociones privadas y por servir de propaganda a la Corona y a las clases dirigentes. El éxito que no obtuvo la citada Real Escuela de las Tres Nobles Artes (1771-1827) en la pintura, con su frío academicismo, lo consiguió en el arte del grabado. Por suerte, dicho centro pudo contar con un especialista en la materia gracias a D. Francisco de Bruna y Ahumada, oidor decano de la Audiencia, teniente de alcaide de los Reales Alcázares y excelso mecenas.

Sabedor por los directores del mismo "de la aplicación y actitud de D. Juan Josef Bécquer, uno de sus discípulos", Bruna resolvió, el 18 de diciembre de 1794, que éste marchase a Madrid. En efecto, en 1796, en la Academia de San Fernando, aprendió el arte, método y forma de abrir a buril con toda perfección. Para ello se le pensionó, costeándose su manutención y sus viajes de ida y vuelta $^{1}$. Tras su regreso a nuestra ciudad, se creó la cátedra correspondiente. El 7 de noviembre de 1802, el referido alumno fue nombrado profesor de Grabado en dulce $^{2}$. Por consiguiente, una vez más, la perspicacia de Bruna hizo posible que se difundieran y valoraran los refinados trazos y colores de unas estampas que, andando el tiempo, se impregnarían del perfume romántico del momento.

\section{SAN NICOLÁS DE BARI}

Cobre (185 x $130 \mathrm{~mm})$, talla dulce, buril.

Papel verjurado (288 x $200 \mathrm{~mm})$, tinta negra.

${ }^{1}$ ROMERO Y MURUBE, Joaquín: Francisco de Bruna y Ahumada, Colegio Oficial de Aparejadores y Arquitectos Técnicos de Sevilla, reedición facsímil de 1965, Sevi1la, 1997, pp. 48 y 91 .

${ }^{2}$ MURO OREJÓN, Antonio: Apuntes para la historia de la Academia de Bellas Artes de Sevilla, Real Academia de Bellas Artes de Santa Isabel de Hungría, Sevilla, 1961, p. 29. 
Obra de José Braulio Amat y Garay.

Firmado en el ángulo inferior izquierdo: "J. Amat [ilegible]".

Inscripción en una cartela inferior: "Efigie del S . S. Nicolas de Bari Segun / se venera en su Templo antigua / Iglesia Parroquial de Sevilla / nuevamente construido y acabado en / el año de 1738 [sic]".

Hacia 1768.

Sevilla. Colección particular del autor.

En julio de 1752 se inició el derribo de la iglesia de San Nicolás de Bari a causa de su estado ruinoso. La reedificación, en estilo barroco, culminó el 26 de noviembre de 1758. Entonces, el templo fue bendecido por D. Pedro del Campo, canónigo-racionero de la catedral de Sevilla. Al día siguiente a la consagración comenzó una Octava en honor del titular, inicio de las fiestas por la erección del nuevo recinto ${ }^{3}$. Consta documentalmente que, con ese motivo, se distribuyeron estampas con la imagen del santo. Los canónigos, reunidos en Cabildo ordinario el 29 de noviembre de 1758, reseñan lo siguiente al respecto: "Los ss ${ }^{\text {es }}$ Contt ${ }^{\text {es }}$ maiores dixeron que por el Diputado de las funciones de estreno de la Parroq ${ }^{1}$ de $\mathrm{S}^{\mathrm{r}} \mathrm{S}^{\mathrm{n}}$ Nicolas, se havian puesto en Contt ${ }^{\mathrm{a}}$ unas estampas del $\mathrm{S}^{\text {to }}$ y el Cab. ${ }^{\circ}$ mandò se repartan a los ss. ${ }^{\text {e" }}$ ( (sic) $)^{4}$.

En esa fecha, el autor del grabado que presentamos tenía once años de edad. José Braulio Amat y Garay nació en Sevilla el 26 de marzo de 1747. Era hijo del maestro platero Blas Amat Lázaro y Ana Garay; y hermano menor de Fernando, también artista platero. Su primer aprendizaje lo realiza en el taller familiar. Con dieciséis años marcha a Madrid para especializarse en el grabado de monedas. En 1766 obtuvo el premio del certamen anual de la Real Academia de San Fernando, en la especialidad de grabado de medallas. En la capital del Reino trabaja de entallador en la Casa de la Moneda hasta 1768, cuando regresa a la capital de Andalucía. En su ciudad natal labora asimismo para la ceca hispalense, alcanzando el grado de ayudante primero de entallador. Contrajo matrimonio en dos ocasiones. La primera, en 1770, con Josefa Díaz de la Fuente; y la segunda, a la edad de cincuenta y tres años, con la viuda Vicenta Macías.

${ }^{3}$ FALCÓN MÁRQUEZ, Teodoro: La iglesia de San Nicolás de Bari de Sevilla. Una parroquia del s. XIII en un templo barroco, Edita Hermandad de la Candelaria de Sevilla, Sevilla, 2008, pp. 51-55.

${ }^{4}$ Archivo de la Catedral de Sevilla: Sección I (Secretaría). Serie Autos Capitulares. Autos Capitulares acordados por los Yll. ${ }^{\text {mos }}$ Señores Dean y Cabildo de la S. ${ }^{\text {ta }}$ Yglesia Metropolitana y Patriarchal de Sevilla, siendo Secretario el S. ${ }^{\text {or }} D .{ }^{n}$ Carlos Reynaud Can. ${ }^{o}$ de tha. S. ${ }^{\text {ta }}$ Yglesia. Año de 1758, f. 359r.

${ }^{5}$ SALAZAR FERNÁNDEZ, Rosa María: "El grabador José Braulio Amat y Garay y las tarjetas de visita en el siglo XVIII", en Archivo Hispalense, n. ${ }^{\circ} 291-293,2013$, tomo XCVI, pp. 442-445. 
Como es sabido, José Braulio Amat también trabajó como grabador de estampas y de ilustraciones de libros. Colaboró, entre otros, con los dibujantes Francisco Jiménez, José Guerra o Francisco Manuel Coelho, con quien realiza en 1771 el plano topográfico de Sevilla por encargo del asistente Pablo de Olavide. Abordó el género del retrato y los asuntos numismáticos. Pero, quizás, es más conocido por sus temas religiosos, puesto que es autor de numerosas estampas de devoción, como la que nos concierne. Su estilo evoluciona desde el preciosismo de las postrimerías del Barroco, propio de la tradición sevillana, donde usa la técnica de buril; hasta la sencillez de líneas de la incipiente estética neoclásica, poética que irá adquiriendo tras su estancia en Madrid, en la que utiliza el aguafuerte ${ }^{6}$.

La imagen que nos ocupa corresponde al primer momento de su producción (Figura 1). Las curvas y contracurvas de roleos, rocallas y ornamentación floral y vegetal que siluetean su asimétrico perfil revelan, ipso facto, el marcado carácter tardobarroco de la estampa. La composición resulta, pues, de un palpitante dinamismo. Destaca el fantasioso empleo de las rocallas, que se funden y entrelazan creando ágiles y sinuosas formas. Abundan en el conjunto como auténticas llamaradas, aportando los apetecidos matices de sutileza y feminidad, tan propios del mundo rococó. Sus atrevidos movimientos acreditan la cronología del ejemplar, ya que dicho elemento decorativo tuvo su apogeo en el reino de Sevilla durante el tercer cuarto del Setecientos, tras la llegada de Cayetano de Acosta a la ciudad del Guadalquivir ${ }^{7}$.

En el centro, tal como reza la inscripción inferior, se representa la efigie de San Nicolás de Bari venerada en la iglesia sevillana de dicha advocación. Este santo nació hacia el año 270 en Licia, Asia Menor, y falleció entre el 345 y 352. En torno al 314 ocupó el Obispado de Mira, hasta su muerte; y en el 325 intervino en el concilio de Nicea. En 1087, para evitar la profanación de los sarracenos, sus reliquias fueron trasladadas desde Mira a Bari. A partir de entonces, su culto, muy difundido en Oriente, se extendió y consolidó en toda Europa. De sus milagros destaca el de las tres doncellas salvadas de la prostitución, ejemplo de su caridad. Un noble arruinado pretendía llevar a sus tres hijas a tan deshonrosa vida para remediar su pobreza. San Nicolás, al enterarse, dotó en secreto a las tres muchachas arrojando, durante tres noches consecutivas, una bolsa de oro para cada una por las ventanas de la casa paterna. Así, podrían contraer digno matrimonio. De ahí que porte tres bolsas o bolas de oro en la mano o sobre el libro ${ }^{8}$.

${ }^{6}$ Ibidem, p. 445.

${ }^{7}$ ROJAS-MARCOS GONZÁLEZ, Jesús: "Un grabado de la Virgen de la Alegría de Sevilla fechado en 1772, obra de J. Audran", en Temas de Estética y Arte, n. ${ }^{\circ}$ XXVII, Real Academia de Bellas Artes Santa Isabel de Hungría y Real Maestranza de Caballería de Sevilla, Sevilla, 2013, p. 127.

${ }^{8}$ FERRANDO ROIG, Juan: Iconografia de los santos, Ediciones Omega, Barcelona, 1950, pp. 207-208 y ERBA, Luisa: "San Nicolás", en Diccionario de iconografía y arte 
En la estampa que analizamos aparece de pie, en suave contrapposto, sobre una superficie paisajística. El grabador interrumpe la trama de buriladas del fondo neutro para aureolar con nimbo la cabeza del santo, que se representa conforme a su iconografía habitual. Es un hombre barbado de mediana edad. Viste como obispo latino de solemne pontifical, con túnica talar, roquete, estola con cruces en los extremos, dalmática y casulla. Es decir, porta todas las prendas distintivas de los órdenes sagrados, ya que el episcopado es la plenitud del orden sacerdotal. Por ello luce en la testa una mitra, símbolo de su autoridad. Se trata, en concreto, de una mitra preciosa, puesto que se adorna con bordados y pedrería y se emplea en los actos solemnes. En la diestra sostiene un báculo pastoral, que alude a su función de gobierno eclesial.

Sobre la casulla, San Nicolás lleva un palio con cinco cruces, que simbolizan las llagas de Cristo. Este ornamento es propio del Sumo Pontífice, quien en ocasiones lo concede a los arzobispos para expresar su participación en la autoridad papal $^{9}$. Su origen se halla, quizás, en el omophorion griego, usado por los obispos de Oriente como emblema de su dignidad y oficio pastoral. Por eso, San Nicolás porta dicho atuendo cuando, en el arte bizantino, es representado como obispo griego $^{10}$. Razón por la que también figura en el presente grabado. El santo exhibe en la mano izquierda, sobre el libro de los Evangelios, las tres bolas de oro alusivas a la dote de las tres doncellas.

Frente a la habitual idealización de este tipo de imágenes, Amat ajusta el buril con cierta objetividad al modelo escultórico original, gubiado en madera policromada $(130 \mathrm{~cm})$. Dicha pieza, que preside el Retablo mayor, se cataloga como obra de fines del siglo XVII y se vincula con un retablo realizado por Sebastián Rodríguez en 1689 para el templo anterior. Fue restaurada en vísperas de la apertura de la nueva iglesia barroca en 1758. A esa intervención deben corresponder los ojos de cristal y el estofado actual ${ }^{11}$. La fidelidad del grabador se aprecia tanto en su composición general como en los pormenores de su indumentaria y atributos iconográficos. Así lo prueban, entre otros detalles, la disposición de las piernas, al adelantar la derecha; o la estampación floral y vegetal de la vestimenta, correspondiente al aludido estofado.

Las diferencias más notables se vislumbran en la omisión de la cruz pectoral, en los dedos primero e índice que sujetan el báculo, aquí cerrados; o en la mitra, anterior a la de plata que porta en la actualidad, cuya inscripción en el óvalo

cristiano, Ediciones San Pablo, Milán, 2012, pp. 1.073-1.074.

${ }^{9}$ FERGUSON, George: Signos y símbolos en el arte cristiano, Emecé Editores, Buenos Aires, 1956, p. 233.

${ }^{10}$ RÉAU, Louis: Iconografía del arte cristiano. Iconografía de los Santos. De la G a la $O$, Ediciones del Serbal, Barcelona, 2001, tomo 2, vol. 4, p. 433.

${ }^{11}$ FALCÓN MÁRQUEZ, Teodoro: Op. cit., 2008, pp. 64 y 100. En 2008 fue restaurada por Pedro Jiménez. 
central dice que fue hecha por los devotos del santo en $1798^{12}$. Todo ello no hace sino aumentar el valor histórico del grabado, ya que, en el plano artístico, Amat pone de manifiesto su variedad de recursos y la sensibilidad de su gama de trazos. En la ejecución, de buriladas suaves, el autor hace especial hincapié en el preciso dibujo de las formas. Gracias al orden de su trama, capta con habilidad los requeridos matices de claroscuro, que potencian los efectos de sombreado y enriquecen así la volumetría del total resultante. Por último, tan solo nos resta señalar que, a juzgar por las similitudes formales y estilísticas, el grabador José María Bonifaz debió tener conocimiento de esta estampa para su versión, fechada en 1795, de la estudiada efigie lignaria de San Nicolás de Bari de Sevilla ${ }^{13}$.

\section{MARTIRIO DE SAN JUAN NEPOMUCENO}

Cobre $(160 \times 109 \times 1,5 \mathrm{~mm})$, talla dulce, buril.

Papel para huecograbado (Michel de $240 \mathrm{gr} / \mathrm{m}^{2} ; 171$ x $220 \mathrm{~mm}$ ), tinta sepia natural (Charbonnel Aqua Wash, Serie 1 n. ${ }^{\circ} 121$ ).

Obra de José María Martín.

Firmado en el ángulo inferior derecho: "J. M. Martín ft".

Inscripción en el borde inferior: "GLORIOSO MARTIRIO DEL S.S. JUAN NEPOMUCENO / como se venera en su Capilla de la Yg. ${ }^{a}$ Parroq. ${ }^{1}$ de S. ${ }^{\text {ta }} \mathrm{M}^{\text {a }}$ de la Blanca / de esta Ciudad de Sevilla. se hizo esta Lámina siendo Mayordomo / D ${ }^{\mathrm{n}}$ Juan Moreno Cura de dicha Yg. a año de 1819.”.

Año 1819 (cobre). Año 2014 (estampación).

Sevilla. Iglesia de Santa María la Blanca (cobre). Colección particular del autor (estampación).

La matriz calcográfica de este grabado, que ahora damos a conocer, ha llegado felizmente hasta nuestros días (Figura 2). Se custodia en la iglesia sevillana de Santa María la Blanca ${ }^{14}$. Se trata de una lámina de cobre amartillada, grabada al buril. El estado de conservación de la plancha es excelente. No obstante, ha sufrido cierto deterioro. Se ha combado transversalmente unos $3 \mathrm{~mm}$. Presenta defectos menores, como rayones o picados. En la superficie se observa alguna oxidación del metal base y un leve azulado. Este último se debe, quizás, al calentamiento al que ha sido sometida la placa durante la estampación original. Por suerte, ninguno de estos daños ha desvirtuado ni deslucido el grabado primitivo.

${ }^{12}$ Ibídem.

${ }^{13}$ Reproducido en CARRETE PARRONDO, Juan; VEGA, Jesusa y SOLACHE, Gloria: Catálogo de la colección de estampas de la Fundación Focus, Fundación Fondo de Cultura de Sevilla, Sevilla, 1996, n. ${ }^{\circ}$ 53, pp. 153-154.

${ }_{14}$ Agradecemos la inestimable colaboración de Francisco Sosa Sánchez, quien nos comunicó la existencia de la plancha de cobre. 
En mayo de 2014, el grabador Guillermo Morán Dauchez eliminó los restos de tinta envejecida y mugre en surcos y ranuras. En el proceso de limpieza usó alcohol etílico de $70^{\circ}$ en primer lugar y, a continuación, agua caliente y jabón neutro. Con las licencias pertinentes, el referido grabador imprimió en esas fechas una nueva serie de la lámina de cobre que catalogamos. En la tirada, compuesta de cinco impresiones, empleó tinta de base óleo e hidrosoluble en sepia natural (Charbonnel Aqua Wash, Serie 1 n. ${ }^{\circ} 121$ ), sobre papel para huecograbado Michel de $240 \mathrm{gr} / \mathrm{m}^{2}$. Culminó su tarea incluyendo, a grafito, la numeración de cada ejemplar en el ángulo inferior izquierdo y, en el derecho, su rúbrica y la fecha: "Imprimit Guillermo Morán / Dauchez AD MMXIV". El resultado de tan exhaustiva labor es, a todas luces, inmejorable (Figura 3).

La obra está firmada por el conocido José María Martín, "último de los grabadores sevillanos" según Ossorio y Bernard. Este autor sostiene que murió en su ciudad natal en 1853, a los sesenta y cuatro años ${ }^{15}$. Sin embargo, con posterioridad se ha afirmado que falleció después de 1860 , fecha de su último trabajo ${ }^{16}$. Sea como fuere, lo cierto es que dicho artífice, procedente al parecer de una familia de artesanos, es uno de los más prolíficos grabadores de la estampa hispalense. Pese a tan dilatada producción, su estilo no evoluciona considerablemente. En líneas generales, permanece anclado a la tradición barroca sevillana de gusto dieciochesco. Sólo con timidez se deja seducir por los nuevos aires academicistas de estética neoclásica. Dotado de un excelente dibujo, prefiere la técnica de buril a la del aguafuerte. Su producción se centra, casi en su totalidad, en los asuntos religiosos, que trata con variedad y riqueza ${ }^{17}$.

Por fortuna, a su extensa producción sumamos ahora este ejemplar, fechado en 1819. El grabado, de formato rectangular y sencillos perfiles rectilíneos, representa el martirio de San Juan Nepomuceno. La leyenda inferior indica que se reproduce tal y como se venera en el templo de Santa María la Blanca. En efecto. Su capilla, antes Sacramental, se ubica en la cabecera de la nave del evangelio. El 31 de diciembre de 1750, D. Martín de Villarreal, fiscal de la Hermandad del Stmo. Sacramento, Sagrado Lavatorio y Ntra. Sra. del Pópulo, donó una talla del referido santo. En torno a esa escultura se funda una hermandad, que levanta un retablo para su titular entre 1756 y $1757^{18}$. Tan bella máquina lignaria, de estilo

${ }^{15}$ OSSORIO Y BERNARD, Manuel: Galería biográfica de artistas españoles del siglo XIX, Ediciones Giner, Madrid, 1975, p. 421.

16 GONZÁLEZ MORENO, Joaquín: "Una colección de grabados de José María Martín”, en Laboratorio de Arte, n. ${ }^{\circ}$ 4, Universidad de Sevilla, Sevilla, 1991, p. 248.

${ }^{17}$ Cf. ibídem, pp. 247-261 y MARTÍNEZ AMORES, Juan Carlos: "La obra pasionista del grabador José María Martín”, en Boletín de las Cofradías de Sevilla, n. ${ }^{\circ}$ 470, Sevilla, Abril 1998, pp. 63-71.

${ }^{18}$ FALCÓN MÁRQUEZ, Teodoro: "Retablos y esculturas de la iglesia de Santa María la Blanca de Sevilla", en Laboratorio de Arte, n. ${ }^{\circ}$ 25, Universidad de Sevilla, Sevilla, 2013, vol. 1, pp. 314-315. 
rococó, está presidida en el ático por un óleo sobre lienzo $(75$ x $78 \mathrm{~cm})$, donde se representa la citada escena martirial. Se trata de la pintura que José María Martín repite, ad pedem litterae, en el grabado que estudiamos (Figura 4). La referida inscripción señala, además, que la lámina se acomete siendo D. Juan Moreno sacerdote de esta iglesia hispalense y mayordomo de la aludida corporación.

Nacido en Bohemia hacia 1345, Juan de Nepomuk ocupó el cargo de vicario general de la Archidiócesis de Praga entre 1389 y 1393, año de su fallecimiento. Cuenta la tradición que fue confesor de Sofía de Baviera, segunda esposa del cruel monarca Wenceslao IV. Gracias a su influencia, la reina rehusaba cualquier contacto carnal con el rey. El soberano, celoso y desconfiado, lo torturó para que revelara el contenido de las confesiones. Al no obtener una sola palabra, fue asesinado y arrojado al Moldava desde el puente de Carlos IV. Al poco tiempo, cinco estrellas iluminaron su cuerpo inerte sobre el río para que fuera recogido y sepultado. Tan trágica muerte le valió ser considerado mártir del sigilo de confesión. En 1729 fue canonizado por Benedicto XIII y, en 1731, elegido patrono secundario de la Compañía de Jesús. Precisamente, los jesuitas han sido los grandes difusores de su culto por Europa e Hispanoamérica ${ }^{19}$.

El grabado rememora el instante en que el santo es lanzado al río desde el pretil del puente. San Juan Nepomuceno aparece en el centro de la composición, representado como hombre joven, barbado y de cabello ondulado. Viste alba con encajes en puños y orilla inferior. Esta prenda es símbolo de la castidad, pureza y alegría eterna de los redimidos por la sangre de Cristo ${ }^{20}$. Sobre los hombros luce una muceta, como vicario general de la archidiócesis praguense. Dicha esclavina, abotonada en su parte delantera, está provista de una capucha ornamental. Se confecciona en seda y piel de armiño en los bordes. Aureola su testa un nimbo de cinco estrellas, que evoca el misterioso fulgor que brillaba sobre su cadáver al flotar en el Moldava. Y porta en la diestra una cruz, como símbolo de la firmeza de su fe.

El santo, maniatado y con la soga al cuello, es tirado al agua por dos verdugos, colocados en posiciones variadas y contrapuestas. Detrás, a la izquierda, un individuo ilumina la escena nocturna con una antorcha. En el lado opuesto, tres soldados armados con lanzas presencian el acontecimiento. San Juan Nepomuceno mira esperanzado a las alturas. En este sentido, las zonas de tierra y de cielo se unen gracias a la antorcha, a las lanzas y, sobre todo, al potente haz de luz que irradia desde lo alto. Dicha luz anuncia ya la inmediata acogida del bienaventurado en la gloria. Así lo confirma un pequeño ángel que, desplegando sus alas, revolotea en la parte superior. El mensajero de la divinidad porta una palma en la derecha y una corona de laurel en la otra mano, símbolos que evocan la victoria

${ }^{19}$ CARMONA MUELA, Juan: Iconografía de los santos, Ediciones Akal, Madrid, 2009, pp. 261-263.

${ }^{20}$ FERGUSON, George: Op. cit., p. 228. 
del mártir sobre la muerte. De hecho, es una de las lanzas la que señala directamente la referida corona, asociando así el sufrimiento del martirio al triunfo de la apoteosis final.

El grupo descrito, al estar formado por siete personas, hace hincapié en la misma idea. El siete es el número de la perfección y de la plenitud, alcanzada por la heroica figura del santo. De ahí que, con el ángel, sumen un total de ocho, cifra alusiva a la vida eterna. La presencia del puente insiste sobre el particular, pues simboliza la unión de dos mundos, superior e inferior. En Israel era la señal de alianza entre el Creador y sus pueblos. Además, al parecer, los tres ojos del puente que se ven en la representación, sugieren los días que Cristo pasó en el sepulcro, previos a su resurrección ${ }^{21}$.

El grabado se ajusta a la pintura original del retablo. La diferencia más notable se halla en la presencia del referido haz de luz. Es más, la versión en la plancha, desde el punto de vista compositivo, mejora a la del lienzo, ya que el formato vertical de la misma enfatiza el sentido ascendente de la interpretación. En cuanto a la técnica, José María Martín hace gala de una fina gama de trazos. Ello le permite enriquecer las tonalidades e incluir mayores efectos de claroscuro y sombreado. Especialmente acertado se muestra en la gravedad de los rostros y, sobre todo, en el tratamiento minucioso de la indumentaria, pues, como buen dibujante, detalla con precisión paños y vestiduras.

En conclusión, de todo lo expuesto líneas atrás, entresacamos el siguiente mensaje subliminal. El martirio es el supremo testimonio de la verdad de la fe, pues llega hasta la muerte. Es, por tanto, la confirmación pública del creyente. En este sentido, San Juan Nepomuceno la acepta ejerciendo un acto de fortaleza. Y abraza a Cristo, muerto y resucitado, por la caridad. De esta manera, se trata de recordar a los fieles que todos los mártires gozan de inmediato de la presencia de $\operatorname{Dios}^{22}$.

Fecha de recepción: 28 de septiembre de 2014

Fecha de aceptación: 28 de noviembre de 2014

${ }^{21}$ CIRLOT, Juan Eduardo: Diccionario de símbolos, Ediciones Siruela, Madrid, 2011, p. 379.

${ }^{22}$ GONZÁLEZ GÓMEZ, Juan Miguel: "La capilla sacramental de San Pedro de Carmona. Nuevas aportaciones sobre su interpretación iconográfica", en Carmona en la Edad Moderna, Actas del III Congreso de Historia de Carmona, Excmo. Ayuntamiento de Carmona, Carmona, 2003, p. 262. 


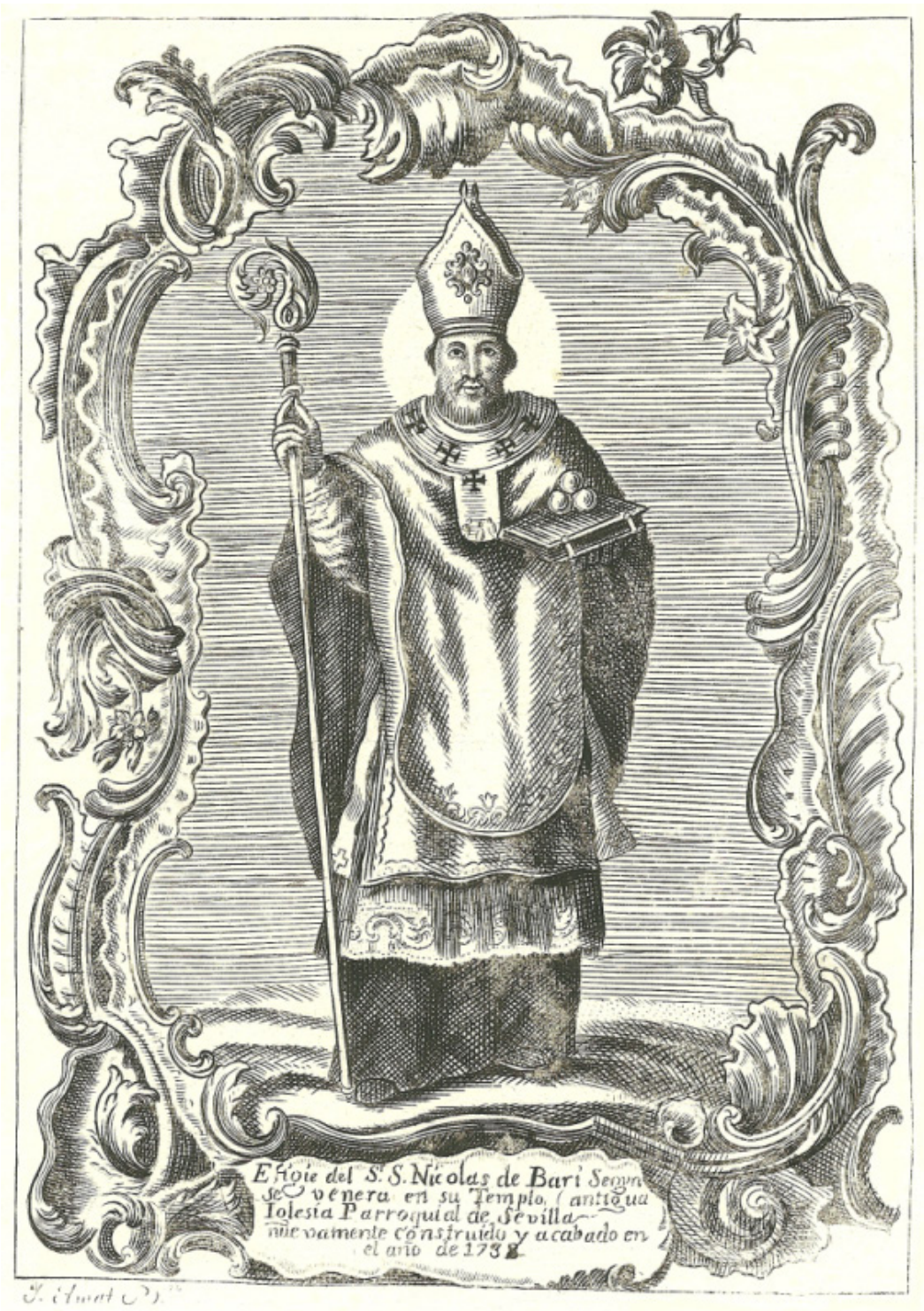

Figura 1. José Braulio Amat. San Nicolás de Bari. Hacia 1768. Propiedad y fotografía del autor. 


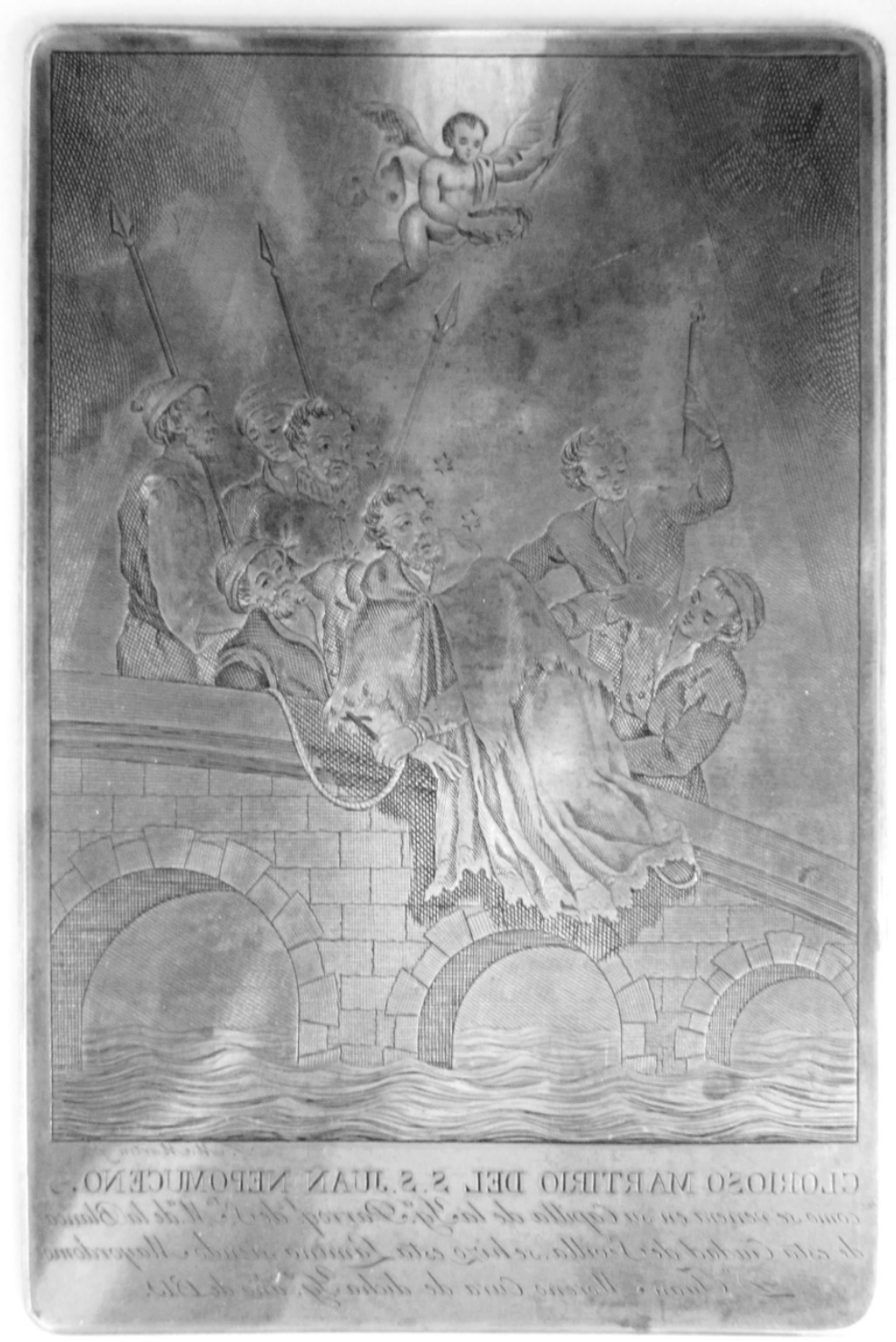

Figura 2. José María Martín. Martirio de San Juan Nepomuceno. Año 1819. Iglesia de Santa María la Blanca. Sevilla. Fot. Jesús Rojas-Marcos González. 


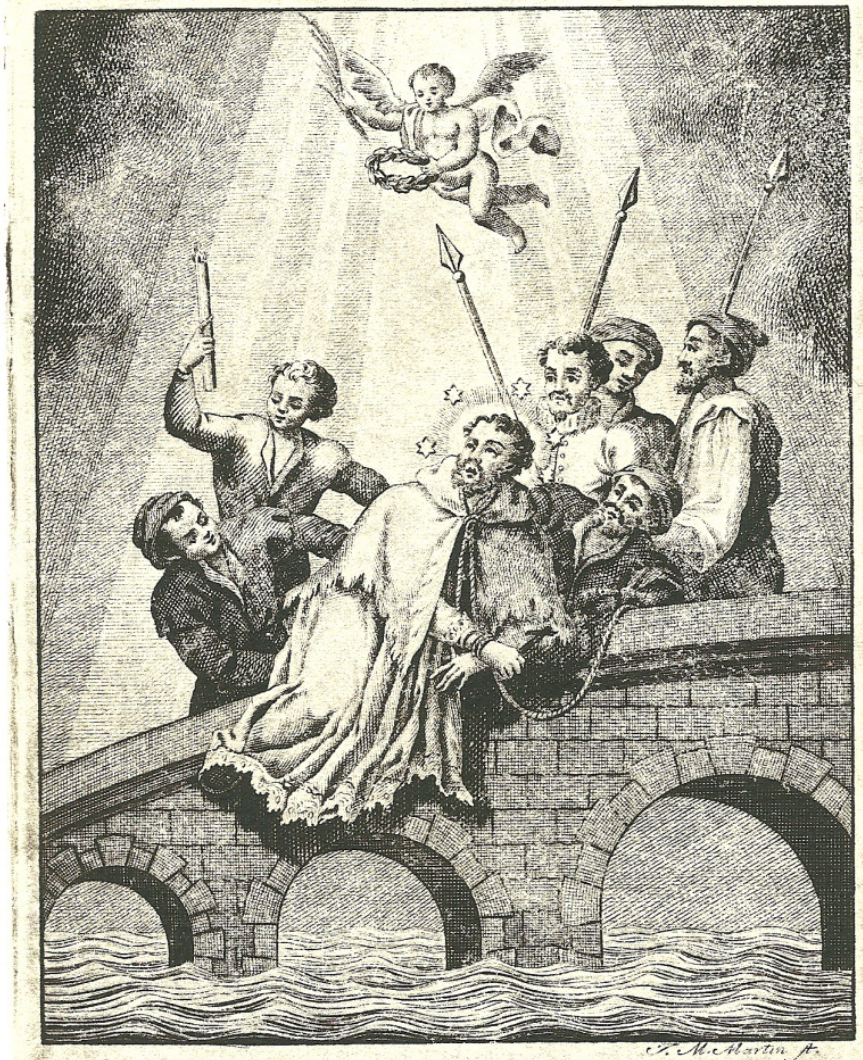

GLORIOSO MARTIRIO DEI S.S.JUAN NEPOMUCENO.9

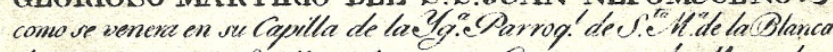
de esta Giudad de Sevilla.se hize esta Lamina sienáse Nayordomo

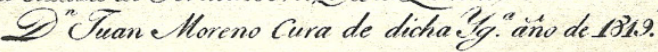<smiles></smiles>

$$
\begin{aligned}
& \text { limprimit Gulllowe Horan } \\
& \text { Dauder AD MUXIV }
\end{aligned}
$$

Figura 3. José María Martín. Martirio de San Juan Nepomuceno. Año 1819 (estampación de 2014). Propiedad y fotografía del autor. 


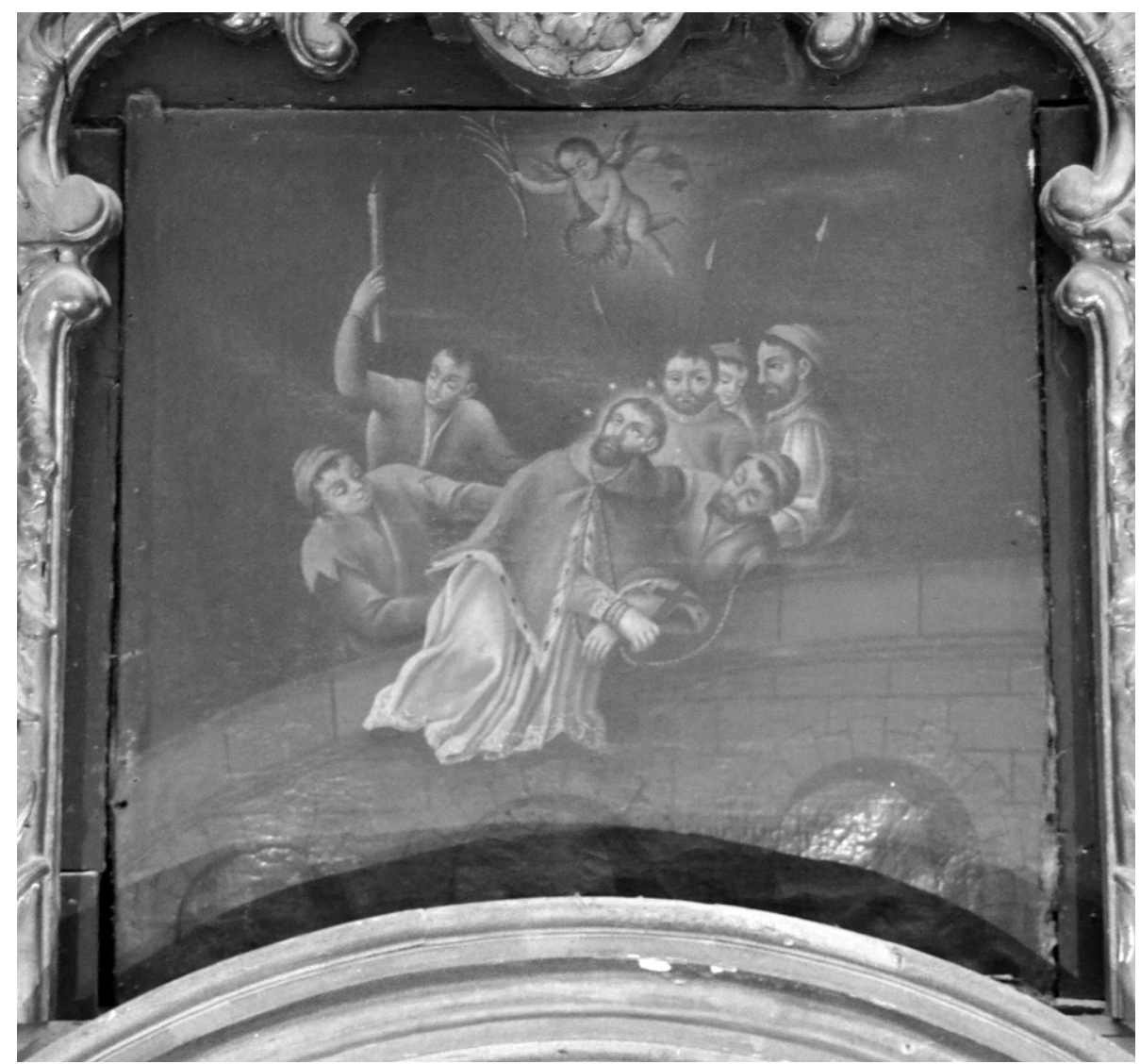

Figura 4. Anónimo sevillano. Martirio de San Juan Nepomuceno. Pintura del ático del retablo de dicho santo (1756-1757). Iglesia de Santa María la Blanca. Sevilla. Fot. Jesús Rojas-Marcos González. 